\title{
LA VALIDEZ DE LA ANTROPONIMIA COMO FUENTE DE ESTUDIO DE LAS LENGUAS ANTIGUAS: EL CASO DE LA PENÍNSULA IBÉRICA*
}

\author{
José María Vallejo Ruiz \\ Universidad del País Vasco \\ josemaria.vallejo@ehu.es \\ THE VALIDITY OF ANTHROPONYMICS \\ AS A SOURCE FOR THE STUDY OF ANCIENT LANGUAGES: \\ THE CASE OF THE IBERIAN PENINSULA
}

La principal vía para aproximarse a la onomástica antigua es el establecimiento de «áreas onomásticas», que definen una región según los nombres, sufijos o procesos morfológicos específicos. Nos consta que, en regiones con cultura epigráfica y lengua propias, las áreas onomásticas vienen a coincidir (con precisión) con la extensión de las lenguas. De esta manera, las áreas onomásticas se convierten en instrumentos válidos de análisis de regiones sin cultura epigráfica.

Palabras clave: lenguas fragmentarias; geografía lingüística; onomástica; nombres propios; antroponimia; áreas onomásticas; Namenlandschaft; epigrafía; Península Ibérica; celtibérico; ibérico; lusitano; astures; gallaeci; vasco-aquitano.
The main way to approach the old onomastics are the «onomastic landscapes», that define a region according to specific names, suffixes or morphological processes. It is clear that, in regions with own epigraphic culture and language, the «onomastic landscapes» come to agree (accurately) with the extension of the languages. This way, the onomastic landscapes become valid instruments of analysis of regions without epigraphic culture.

Keywords: fragmentary languages; linguistic geography; onomastics; proper names; personal names; onomastics landscapes; Namenlandschaft; epigraphy; Iberian peninsula; Celtiberian; Iberian; Lusitanian; Astures; Gallaeci; Basque-Aquitanian.

* Este artículo se ha elaborado en el marco de un contrato de investigación Juan de la Cierva concedido por el Ministerio de Educación y Ciencia, desarrollado en el Departamento de Estudios Clásicos de la Universidad del País Vasco-Euskal Herriko Unibertsitatea. En el capítulo de los agradecimientos personales debo citar a Juan José Palao, Joaquín Gorrochategui y Carlos García Castillero, quienes, por ese orden, leyeron las primeras versiones del manuscrito; ni que decir tiene que me responsabilizo de todo lo que en él se dice y que les exculpo de cualquier error o imprecisión. 
1. Los nombres propios conforman, dentro de un sistema lingüístico y sincrónicamente hablando, un grupo especial. Ello se debe a que, a diferencia de los nombres del léxico común, no sirven para «significar», es decir, la secuencia fónica utilizada no aporta información del sujeto al que alude, sino que simplemente lo «identifica»o «individualiza». El número de antropónimos (nombres de persona) existentes en las lenguas no es tan variado como para individualizar a todos los habitantes, y forzosamente existirán personas que porten el mismo nombre; no obstante, la práctica nos dice que estos individuos no comparten ninguna característica física o de personalidad, en virtud, como ya he adelantado, de esa ausencia de significación.

2. Esta falta de semántica de los antropónimos, muy acentuada en nuestro ámbito cultural occidental, es evidente desde el momento en que son impuestos previamente al nacimiento, con independencia del momento de éste, de la apariencia física del recién nacido o de las expectativas puestas en él, y, por supuesto, no proporcionan información alguna sobre las características físicas o morales de quien los porta: uno puede llamarse Victor sin haber ganado batallas, Justa o Clemente sin estar por ello obligado a impartir justicia, o Milagros sin que se le presuponga ningún poder divino especial. Pero la mayoría de los nombres se adjudica sin más justificación que la mera eufonía, o como consecuencia de algún tipo de homenaje a familiares, amigos o al santo del día. Puede decirse que no tenemos conciencia del significado por muy evidente que éste sea: así, Pilar o Vicente pueden pasar inadvertidos desde el punto de vista de la semántica. Incluso en algunos casos como Ascensión o Concepción, donde se llega a tener conciencia del sentido, el peculiar gusto por abreviar expresivamente estos nombres más largos $(\rightarrow$ Ascen, Conchi) contribuye a ocultar su sentido primigenio.

Esta tendencia a ignorar (consciente o inconscientemente) el origen semántico de los nombres, unida al uso aleatorio que de ellos hacemos al asignarlos a nuestros hijos, trae como resultado que el nombre haya perdido todo valor semántico ${ }^{1}$, pasándose a la utilización de formas abreviadas o alteradas que nos resultan mucho más cercanas e identifican mejor al individuo: el

1 Pulgram 1954, p. 165, recoge esta idea y pone de manifiesto cómo la relación del nombre con radicales conocidos y utilizados en el léxico común es más obvia para el hablante de lenguas semitas, chino o algunos dialectos africanos. En nuestro entorno, la pérdida de conciencia del significado primitivo del término usado como antropónimo es mayor en el caso de importaciones o préstamos; si nombres como los citados Victor o Clemente carecen de 
nombre Carlos puede aludir a cualquiera de los que así se llamen, pero los Charli o Carlitos suelen estar relacionados con un entorno más restringido. Los lingüistas encargados de estudiar el origen de cada forma ven así dificultada su labor porque la falta de sentido de algunos nombres impide establecer cognados con otras lenguas y, como consecuencia, dificulta el análisis.

3. El nombre, por tanto, no aporta característica alguna del individuo y, contrariamente a lo que pudiera pensarse a priori, tampoco sobre la lengua que habla. Por sorprendente que parezca, en la base de casi todos los sistemas onomásticos del mundo occidental subyace un elenco de nombres que trasciende fronteras, por causas históricas y culturales (de ahí la abundancia de nombres surgidos de las lenguas germánicas, del latín o del griego), religiosas (nombres formados en el entorno de la lengua hebrea) o exotismo (antropónimos árabes o hindúes), lo que deja sin fruto un análisis etimológico que pretenda establecer, a partir del origen lingüístico del nombre, la lengua del portador.

Es cierto que cada rama dialectal ha sufrido diversas evoluciones fonéticas y que, en algunos casos, esto facilita que un antropónimo se asocie con una lengua concreta: el nombre Antoine es una evolución francesa del nombre latino Antonius. Pero los que hemos curioseado en la onomástica personal nos hemos dado cuenta de que la asignación de antropónimos a lenguas concretas no es lo habitual al tratar con estas formas modernas, dado que, por otro lado, otra variante como Antonio puede hacer alusión a un individuo español, italiano o portugués. Independientemente de esta limitación, producida en lenguas cercanamente emparentadas, no es posible asignar de antemano una lengua concreta a los portadores de esos nombres - aunque puedan seguirse ciertos criterios geográficos a modo de ayuda ${ }^{2}$-, dado que las modas, la migración, el bilingüismo o el colonialismo se encargarán de encontrar sufi-

cualquier referencia apelativa para la mayoría de los hablantes, aún es más claro en ejemplos como Rodrigo, Alberto, Soraya o Teófila.

${ }^{2}$ M. . $^{\mathrm{a}}$ Lourdes Albertos es, por su abundante producción de obras onomásticas, una referencia que no debe olvidarse a pesar del paso del tiempo. Sus reflexiones sobre ámbitos generales de la antroponimia y el manejo de una enorme cantidad de datos la colocan entre las personas más influyentes en el desarrollo posterior de estudios onomásticos. Con respecto al apartado que estoy desarrollando, voy a permitirme transcribir un párrafo de su obra de 1976, p. 62: «Así puedo decir que no conozco ninguna chica que se llame Izaskun, Icíar o Estíbaliz que su familia no haya tenido alguna relación, siquiera sea accidental, con las Provincias Vascongadas; ninguna Sonsoles que no tenga que ver con Ávila, ninguna Hontanares 
cientes irregularidades. De éstas no es la menor el hecho de que entre lenguas emparentadas surgen casos en los que la evolución fonética no ha modelado una forma lo suficientemente característica, como en el ejemplo anterior.

4. Este hecho impide que podamos tomar un único nombre como representativo de un sistema onomástico o de un conjunto lingüístico, pues en último extremo podría tratarse de una forma azarosa o incluso de un préstamo o una moda ${ }^{3}$ : un grano no hace granero. A la hora del análisis de la onomástica personal de un grupo poblacional determinado por algún tipo de frontera étnica, geográfica o política es imprescindible hacer entrar en juego muchos más datos de cuya conjunción podamos obtener conclusiones representativas. Dado que el nombre no aparece aislado, sino que está imbricado en toda una serie de circunstancias, puede ser estudiado desde diversos puntos de vista: el primero de ellos es revelar la materia fónica que subyace a cada conjunto de signos gráficos cuando el análisis se hace a partir de formas escritas; la grafía Joseph/José/Josep no presupone la misma pronunciación en inglés, francés, español, portugués o catalán, como tampoco Albert en inglés y en francés. Además, cada lengua ha sufrido diferentes evoluciones fónicas desde el momento en que se fijó gráficamente el nombre; desde luego, la situación es extrapolable a los nombres propios de la Antigüedad, transmitidos sobre todo a través de la epigrafía ${ }^{4}$. La dificultad de conocer el sonido que corresponde a la grafía es mayor y, por tanto, desconocemos si un Matugenus galo o uno lusitano pronunciaban de la misma manera su nombre.

o Fuencisla que no tenga relación con Segovia, ya que todas estas advocaciones de la Virgen María tienen un fuerte sabor local o regional».

3 Y aquí es donde fallaría un sistema de identificación geográfica llevado al extremo de considerar una única forma como si fuera suficientemente representativa. La introducción de una forma como Kevin en España, Francia o Alemania hace unos años supuso la confirmación de que un nombre totalmente nuevo puede implantarse como una moda. En el aspecto onomástico, la moda no es simplemente pasajera, dado que la permanencia del nombre está asegurada durante toda la vida del portador, y puede, eventualmente, transmitirse a generaciones sucesivas.

${ }^{4}$ La fijación de la forma correcta del nombre es aún más difícil en algunos antropónimos de transmisión literaria, fundamentalmente por dos motivos: 1) es posible que los autores que transmiten los nombres hablen una lengua diferente y la adaptación fónica no sea del todo fiel, y 2) los manuscritos que han transmitido la fuente han sufrido posteriores adaptaciones y modificaciones (cf., para algunos casos de la Península Ibérica y de Galia, Evans 1964 o Vallejo Ruiz 2002). 
Un segundo elemento que ayuda a definir un sistema onomástico es la diferente manera de amalgamar compuestos o denominaciones múltiples: combinaciones como José Manuel o Juan Antonio son más normales en la Península, mientras que Carlos Alfredo o Luis Mario se encuentran preferentemente en regiones de la América hispano-hablante 5 .

El tercer criterio es la formación de hipocorísticos o nombres familiares, diferentes de una lengua a otra incluso sobre bases comunes. El nombre Nicole genera en francés Nicolette, y en inglés Nicky, de la misma manera que Manuel produce Manu o Many en distintas regiones castellanoparlantes de España y de América. Incluso dentro de una zona lingüísticamente más uniforme, los derivados diminutivos varían enormemente de una región a otra: Miguelico, Miguelín, Miguelito o Miguelchu. El conjunto de sufijos y su frecuencia se convierten así en otra fuente de información en tanto en cuanto se trata de pequeños ladrillos en la construcción de antropónimos, si bien no en la estructura básica sí como modificador derivativo-afectivo de los nombres. Este recurso afectivo engloba también a la manera de fundir los compuestos, como en el caso de Chemi por José Miguel o de Marisa por María Isabel.

El cuarto es la particular elección de las raíces de los nombres, en algunos casos etimológicamente identificativas y, en ocasiones, aisladas en cuanto a su origen: Indalecio es básicamente español, Viriato es portugués, y Cuauhtémoc es mexicano. A propósito de la etimología, cabe decir que, como ya he adelantado, en pocas ocasiones tiene conciencia el hablante occidental del origen de un nombre propio, ni siquiera en los casos más evidentes (Elena, Áurea o Marino); es ésa una de las razones por las que tienen mucho éxito los préstamos entre lenguas y las modas dentro de una comunidad. Aquéllos (los préstamos) no implican necesariamente una mayor similitud formal, pues las pequeñas coincidencias entre lenguas no emparentadas directamente, como el inglés o el francés (Albert), resultan ser en ocasiones grandes divergencias (ing. Stephen/fr. Etienne), lo cual puede verse incluso entre lenguas emparentadas (fr. Jacques/esp. Santiago). Se da a veces la circunstancia de que pueden llegar a confundirse en una lengua dos términos etimológicamente alejados (cf. Mario/María) o que un hipocorístico englobe dos orígenes dis-

\footnotetext{
${ }_{5}^{5}$ En español no existen nombres compuestos en una sola palabra; los antiguos Teodoro o Roberto han perdido su sentido compuesto, y lo mismo pasa con nombres compuestos de léxico común como Montserrat, que no son sino fósiles.
} 
tintos (Anabel por Ana Isabel o Ana Belén). No es tampoco extraño el gusto por la traducción de algunos nombres en casos de préstamo o lenguas en contacto (como el vasc. Nekane por esp. Dolores).

Por último, podemos citar el cronológico como otro de los criterios caracterizadores de los sistemas onomásticos. Las diferentes épocas muestran gustos peculiares por unos nombres u otros y así, mientras que Eustaquio, Cristóbal o Eladio pudieron ser más habituales en épocas pretéritas en español, Miguel es más atemporal y Jonathan moderno. Además, hablando del factor cronológico, debemos tener en cuenta el fenómeno de las modas, en particular aquellas que no se extienden más que unas pocas generaciones.

5. Unidos a modo de decálogo todos los criterios anteriores como instrumento de análisis del sistema onomástico, podemos concluir que el conjunto de los nombres (simples, compuestos, hipocorísticos o diminutivos) más característicos en cada región, unido al de los sufijos, sería ilustrativo de la diferente pertenencia de esa área a un grupo lingüístico o a otro, en virtud de las diferencias fonéticas, morfológicas, gráficas e incluso de derivación. Un conjunto de nombres que rezara Miguel, Santi, Jósean, Jennifer, Pili, Curro, Mariaje, Alberto, Aymar, Pedrín, Fernan, Carlitos, y así hasta un número representativo $^{6}$, apuntaría sin grandes dudas a la Península Ibérica ${ }^{7}$. El dato más llamativo lo constituiría el hecho de que todo este elenco no nos concretaría a priori qué lengua hablaban los portadores de estos nombres, a no ser por otra serie de factores externos a la onomástica ${ }^{8}$.

${ }^{6}$ La cantidad es fundamental; cuanta mayor sea la información que se maneja, más preciso resultará el análisis. De la misma manera, una reducción en el número de testimonios podría condicionar el éxito del análisis.

7 De igual modo, Arja, Hannele, Heikki, Helli, Liisa, Markku, Penti, Raija, Risto y Taina apuntarían a Finlandia; Camille, Chloé, Emma, Kevin, Léa, Lucas, Manon, Maxime, Théo y Thomas a Francia; o Agné, Arbidas, Azuolas, Juozapas, Jurgis, Liudvika, Mantas, Mindangas, Tomas y Veronika a Lituania. Untermann 1965, p. 12, se expresaba de una manera similar: «Hoy día existe igualmente un repertorio onomástico castellano, francés o alemán, cada uno compuesto por nombres de procedencia variadísima - hebraica, griega, latina, germánica-, pero cada uno marcando de manera inconfundible la propiedad inalienable del grupo humano que lo emplea».

${ }^{8}$ En este sentido, existen casos que resultan llamativos, y que a menudo se producen en regiones bilingües, sin necesidad de entrar a valorar aquí el grado de bilingüismo o diglosia: si uno se fija en los nombres que portan personas nacidas en el País Vasco en determinadas generaciones y cuya lengua madre era el vasco, se percatará de la existencia de nombres cristianos a la manera de los de Castilla o de Andalucía: es más, suele tratarse de nombres 
Como ya he sugerido antes, regiones con la misma lengua pueden tener hábitos diferentes en la elección de raíces o combinaciones onomásticas. Luis Alfredo o Diego Armando no son comunes en la Península y Cuauhtémoc nos orienta a México; también hay algunas variaciones entre los nombres del norte y los del sur de la Península. Por ello, parece que podemos concluir que una región antroponímica corresponde a una sola lengua, pero que una lengua muy extendida puede simultanear variaciones onomásticas, aunque con un fondo esencialmente común. Esta característica, compartida por todas las lenguas que tienen una gran distribución geográfica, no está tampoco ausente de las antiguas, como en el caso del latín. En su dispersión por todo el Imperio, esta lengua conoció variaciones en la concentración y porcentaje del uso de antropónimos. No existen las mismas posibilidades de encontrar a un Iulius, un Aurelius o un Seuerius en el siglo I a. C. que en el III d. C. ${ }^{9}$ Los motivos de las pequeñas variaciones son, además de cronológicos, de otros múltiples orígenes; entre ellos, y no el menos importante, la adaptación fonética o la traducción semántica ${ }^{10}$ de algunos antropónimos indígenas de sustrato. De ahí que se encuentren en algunas regiones nombres típicamente romanos en proporciones inusuales en la misma Roma; a menudo se ha mencionado la presencia del latino Amoena en Hispania ${ }^{11}$, cuya dispersión no encaja con lo habitual en un nombre romano y sólo parece justificarse como la traducción de un nombre indígena con una gran frecuencia en la lengua de origen. En el caso de África es particularmente llamativa la concentración de Felix, que seguramente se explique de una manera similar (Kajanto 1965, p. 272 y CIL VIII). La abundancia de Verecundus en Galia también podría deberse a fenómenos del mismo tipo de traducción o reinterpretación; Weisgerber señaló que los Verecundus en la zona del Rhin deben su éxito a la similitud fónica, dado que se reinterpreta como un nombre galo por el significado que un falso corte morfológico puede proporcionar: uer- en galo significa 'muy' y condo

\footnotetext{
algo menos comunes porque con frecuencia están extraídos del santoral. Tovar mencionaba los nombres cristianos de ciertas comunidades de Sudamérica que, sin embargo, utilizaban como primera lengua el quechua.

${ }^{9}$ Para este tipo de conclusiones cf., entre otros, el reciente estudio de Navarro, Oria y Ramírez 2003 para la onomástica de Lusitania. Siempre es útil Untermann 1965.

${ }^{10}$ Cf. Weisgerber 1969, pp. 103-149; entre los tréveros hay abundancia de Vrsus porque son traducciones del celta Arto, muy utilizado en la región.

${ }^{11} \mathrm{Cf}$. OPEL I 102. Se trata de un nombre muy poco frecuente en el Imperio romano que se documenta especialmente en la Península Ibérica y concretamente en la región lusitana.
} 
'inteligencia' ${ }^{12}$. Lo contrario (la escasez de algunos nombres romanos en algunas regiones) es, evidentemente, la otra cara del mismo fenómeno, al que puede añadirse la adopción de nombres indígenas que, ya en el flujo de la lengua latina, fueron más fácilmente exportables (cf. el éxito de Reburrus, con una reinterpretación latina en cuanto a la segmentación y al significado ${ }^{13}$ ).

6. Por tanto, cada una de las regiones antroponímicas muestra, a la hora de formar nombres, preferencia por un conjunto de recursos, como son la elección de raíces y de sufijos, y la posibilidad de que sean modificados de acuerdo con unas reglas fonéticas específicas del territorio. A las regiones poseedoras de un sistema onomástico propio en los términos que acabo de definir se las denominó ya hace tiempo «áreas antroponímicas». El concepto se diseñó para el estudio de la onomástica antigua ${ }^{14}$, y el nombre fue introducido por J. Untermann y definido en su obra Elementos de un atlas antroponímico de la Hispania antigua ${ }^{15}$, aunque ya en 1961 había

\footnotetext{
${ }^{12}$ Cf. también Lefebvre 2001, pp. 597-598 y, en la misma línea, Raepsaet-Charlier 1995.
}

${ }^{13}$ Cf. Rubio Alija 1959 o Vallejo Ruiz 2005, pp. 388-390. Tradicionalmente se unió al apelativo y antropónimo burrus; ya $I E W$, p. 133 incluyó s. u. * $b^{h} e r$ - 'rajar, partir, frotar' los apelativos burra y reburrus, que habían penetrado en el léxico latino tardío y a los que se les consideraba hispanos. Reburrus sería un compuesto con re-, con el significado general de 'rebelde, de cabello rizado'. Zeuß y d'Arbois de Jubainville (apud AcS II 1089) pensaron que la segmentación debía ser más bien Reb-urrus; Rubio Alija 1959, p. 110 y Albertos 1965, pp. 119-120, se basaron en la presencia de Rebilus para reforzar la idea que Reburrus no tiene relación con Burrus. Además, re- es en origen un prefijo documentado únicamente en itálico, no compartido por el resto de las lenguas indoeuropeas, y que, en principio, se considera un elemento que entra en composición con verbos y no con nombres.

${ }^{14}$ En Hispania, M. Gómez Moreno comenzó a asignar nombres a áreas concretas (v. 1949, especialmente el mapa de su p. 241, con la representación de Ambatus, Boutius, Doidena y Tritius, nombres que ya llamaron su atención), lo que constituyó la semilla de la aplicación de la cartografía a la onomástica. Unos años más tarde, Rubio Alija 1959 utilizó el mismo sistema para esbozar un panorama cartográfico de los principales nombres indígenas hispanos.

${ }^{15}$ Untermann lleva a sus últimas consecuencias la aplicación del nuevo concepto en diversas zonas, como la véneta, la hispana o la iliria; en 1965, pp. 11-12, recogía la definición de «área antroponímica» (o Namenlandschaft): «una región geográfica caracterizada por un repertorio de nombres personales a disposición de los habitantes del área durante una cierta época. Tal repertorio está constituido por una determinada cantidad de nombres y por ciertos medios morfológicos para la variación de nombres, sobre todo para la formación de hipocorísticos. Además, no pasemos por alto que un área antroponímica puede tener su propio formulario usado en la denominación privada u oficial de personas como, verbigracia, en Roma, la fórmula 
proporcionado una primera visión gráfica sobre la distribución onomástica hispana ${ }^{16}$. Para ilustrar la noción de este concepto he recurrido a sistemas onomásticos actuales, con los cuales nos resulta más sencillo comprender e interiorizar los procesos de creación, alteración y préstamo de nombres. Con ellos podemos evaluar hasta qué punto es válida la ecuación que identifica un área antroponímica con un territorio lingüístico. La manera de abordar esta última equiparación y adaptarla a épocas pretéritas pasa por utilizar los distintos puntos del decálogo a modo de decodificadores, valiéndonos de los avances de las disciplinas filológicas y lingüísticas (la fonética histórica, la morfología nominal o la geografía lingüística). En último caso, debemos recurrir también a los conocimientos históricos sobre la región en lo referente a movimientos migratorios y contactos de pueblos a efectos de acomodar los datos provenientes de la lingüística ${ }^{17}$.

Pero la aplicación de estos principios metodológicos no siempre se ha efectuado con las suficientes garantías; en un rápido vistazo cronológico al estudio onomástico peninsular, nos percatamos de que los primeros análisis adolecían de cierta falta de rigor histórico y lingüístico, y estaban teñidos de ciertos apriorismos precientíficos; la interpretación de la Península Ibérica como un territorio donde la lengua vasca o vasco-ibera se había hablado única y uniformemente condicionó las opiniones de los eruditos hasta pasado el siglo XIX. A falta de un corpus completo y fiable tal y como lo conocemos hoy, el primero en aplicar un criterio discriminador a la onomástica fue W. von Humboldt; él observó que tanto la presencia de $r$ - inicial (Rectugenus) como de grupos consonánticos con líquida (por ejemplo br- en los topónimos compuestos con -briga, como Flauiobriga) no podían corresponder a la lengua ibérica, dado que estaban ausentes en los términos patrimoniales del vasco actual. Esto era tanto como decir que la presencia de un sistema onomástico diferente del ibero exigía, en consecuencia, suponer la existencia de otra lengua.

de los tria nomina. En cambio, la procedencia etimológica de los elementos que componen un repertorio carece de interés alguno para la definición de un área antroponímica; los elementos pueden ser derivados de palabras o raíces latinas, griegas, célticas, ibéricas: siempre que su empleo se reduzca a un área caracterizada también por otros fenómenos onomásticos, aquellos elementos se convierten en rasgos típicos del área dentro de la cual ocurren».

${ }^{16}$ Otras obras importantes sobre aspectos de las áreas antroponímicas son Alföldy 1964; Katičić 1963, 1965; Untermann 1961b.

${ }^{17}$ Véanse, no obstante, las observaciones críticas de Kajanto 1967. 
Esta primera intuición que, tomando como base características fonéticas, dividía dos sistemas onomásticos se mantiene hasta nuestros días y sirve para estructurar a la Península Ibérica en dos dominios lingüísticos antiguos (indoeuropeo y no indoeuropeo), fruto de la presencia de dos (o más) grupos de lenguas. La prueba definitiva, que con posterioridad a Humboldt nos ha corroborado esta división lingüística, ha venido, sobre todo, del desciframiento de la escritura ibérica, hecho que dejó a la vista que bajo el mismo sistema gráfico subyacían dos lenguas diferentes, celtibérico e ibérico. Posteriormente, el nuevo material epigráfico que ha ido viendo la luz ha confirmado una y otra vez la división lingüística que Humboldt había esbozado.

7. Si, llegados a este punto, aplicamos al descubrimiento de Humboldt (es decir, la definición de distintas realidades onomásticas antiguas de la Península Ibérica) lo que ya sabemos sobre áreas antroponímicas actuales, resulta que podemos caracterizar e individualizar sin mayores dificultades las distintas áreas onomásticas antiguas: en cuanto a la antroponimia de la región ibérica, las evidencias permiten decir que está formada por nombres predominantemente compuestos (tetrasílabos, con dos elementos bisílabos en cierta medida intercambiables); dispone, a su vez, de un elenco claramente representativo (con segmentos como gibas, sosin, adin, ordu, balci, tibas, biur..$\left.{ }^{18}\right)$. La fonética sin consonantes aspiradas, que evita grupos consonánticos y fonemas como $d$ - o $r$ - en inicial, es también representativa del sistema onomástico.

Si, por el contrario, definimos la lengua de los antropónimos celtibéricos (al oeste de la frontera lingüística trazada por el ibero), nos encontramos con una serie de características lingüísticas que, consideradas en su conjunto, le confieren también una total peculiaridad: presencia en la onomástica de nombres en genitivo del plural que hacen referencia a grupos de parentesco más amplios que la familia nuclear (aunque el fenómeno no es exclusivo de Celtiberia, sí lo son nombres como abokum, alaskum, ataiokum, atokum, ensikum, mailikum, telkaskum, etc. ${ }^{19}$ ), al lado de un elenco propio de antropónimos ${ }^{20} \mathrm{y}$ de un sufi-

\footnotetext{
${ }^{18}$ Ver Untermann 1987. A modo de resumen es útil Velaza 1996, pp. 37-38.

${ }^{19}$ En las citas de nombres antiguos, la minúscula suele utilizarse para transliterar un sistema de escritura no latino, como el semi-silabario ibérico.

${ }^{20}$ Los últimos años han sido especialmente fructíferos en el hallazgo de material onomástico celtibérico en época bastante temprana (siglos II y I a. C.). Existen algunos nombres exclusivos con muchas apariciones epigráficas: abulu, akuios, -a, arkanta, burzu, elazunos,
} 
jo como -o-ko-, que sólo se documenta en la región. En cuanto a la fonética, tampoco encontramos consonantes aspiradas y es muy escasa la presencia de $f$; al contrario de la región ibérica, aquí sí hallamos grupos consonánticos (característica esta que, por sí sola, tampoco es exclusiva).

En este caso, la presencia de dos lenguas epigráficamente atestiguadas revela que la intuición onomástica de diferenciar ambos sistemas era correcta, y que la extensión geográfica de esas características antroponímicas coincide con la extensión geográfica de las lenguas correspondientes. No es difícil, por tanto, completar la ecuación: el sistema antroponímico hallado en la región denominada celtibérica por las fuentes clásicas es el de los hablantes de la lengua celtibérica en un momento concreto, del mismo modo que el sistema antroponímico de la región ibérica es el de los hablantes de la lengua ibérica. En esta línea se expresaba ya Untermann 1998, p. 79, cuyas palabras sobre este particular son ciertamente aclaradoras: «La extensión geográfica de los antropónimos ibéricos, tal y como se definen por el repertorio de elementos que acabamos de exponer, coincide perfectamente con el dominio atribuido a los hablantes de la lengua ibérica que podemos delimitar». Creo que la primera inferencia lógica de estas premisas no es otra sino que un territorio lingüístico se revelará uniforme en la medida en que su sistema antroponímico lo sea ${ }^{21}$.

8. A estos dos sistemas antroponímicos que cuentan con atestiguaciones epigráficas directas en la Península Ibérica puede añadírseles la existencia de la «escritura del suroeste», que parece revelar la presencia en la zona del sur de Lusitania de una lengua distinta del celtibérico y del ibérico, sobre la que planean, aún hoy, más sombras que luces. La primera sombra es la dificultad de asignar la lengua de estas inscripciones epicóricas (escritas en un signario de difícil lectura e interpretación), con predominio en el sur de Lusitania ${ }^{22}$, a la del sistema onomástico ${ }^{23}$ presente en el valle del Guadalquivir y, por tanto, no coincidente en exactitud geográfica.

\footnotetext{
-a, kalaitos, koitu, koitina, Letondo, mezukenos, Rectugenus, Segontius, Stenionte, terkinos, toloku, tueizu о useizu.

${ }^{21}$ Sin embargo, ello no quiere decir, como ya hemos visto, que todos los antropónimos se hayan formado etimológicamente en el seno de estas lenguas, sino que las preferencias, el origen, su combinación y su uso han sido peculiares.

${ }_{22}$ Puede verse un repertorio con las inscripciones halladas en esta región en $M L H$ IV.

${ }^{23}$ Tanto toponímico como antroponímico, transmitido fundamentalmente por las fuentes clásicas o la epigrafía, es decir, por vía indirecta.
} 
La segunda sombra es la de su filiación genética, con la duda de alinearla al oeste (lengua indoeuropea como el celtibérico) o al este (lengua ibérica o emparentada); algunas secuencias legibles en la epigrafía local sudlusitana podrían interpretarse como formas indoeuropeas ${ }^{24}$, pero el conjunto antroponímico del valle del Guadalquivir tiene un carácter peculiar que parece diferenciarlo del grupo indoeuropeo. Algunos autores ${ }^{25}$ han avanzado las características principales de estos nombres, como son las geminaciones y aspiraciones; sus raíces presentan un aspecto poco común: Attita, Attisaga, Baritto y nombres con un elemento Sis-; a ello se añaden algunos grupos consonánticos no habituales (Insghana, Ildrons) o sufijos peculiares (-itt- y -ag-). A pesar de su escaso aspecto indoeuropeo, la realidad es que no hay tampoco ningún indicio que nos haga suponer una proximidad ibérica para estos nombres; habremos de esperar todavía algún tiempo para avanzar en su definición. Mientras tanto, nos conformaremos con atisbar, entre estos datos, la existencia de al menos una lengua que coincide con un área antroponímica propia del Guadalquivir, ante la imposibilidad de decidir si la epigrafía sudlusitana se corresponde o no con ella.

9. Teniendo en cuenta las posibilidades de éxito del análisis que estamos poniendo en práctica, Untermann 1998, p. 74, añadía con optimismo contagioso: «A tales diferencias de lenguas [las tres hasta ahora mencionadas] casi perfectamente corresponden dominios onomásticos, tanto en la toponimia como en los nombres de personas». Es entonces en este punto cuando el título de la presente reflexión cobra todo su sentido: ¿hasta qué punto podemos extrapolar a otras regiones lo aquí aceptado, es decir, la equiparación entre área onomástica y sistema lingüístico? Para averiguarlo hemos de considerar el estudio del resto de las regiones de la Península Ibérica con los mismos criterios que definen un área antroponímica. Hallamos entonces con cierta desilusión que el planteamiento no es tan productivo como hasta ahora: en la mayoría de las regiones no tenemos atestiguado un sistema epigráfico propio. Sólo en el caso del lusitano tenemos pruebas para considerar que tuvo algo similar a un sistema epigráfico, que refleja en unas pocas inscripciones ( $\mathrm{y}$ ya todas en caracteres latinos) la existencia de una lengua indoeuropea (propia, por tanto, de la región occidental de Hispania) diferente de la celtibérica y de la

\footnotetext{
${ }^{24}$ Véase el estudio de J. Untermann en MLH IV, pp. 167-168, con extensa bibliografía.

${ }^{25}$ Cf. Albertos 1966, pp. 275-277; De Hoz 1989, p. 553.
} 
del suroeste y, con bastante probabilidad, no celta. Esta lengua, enormemente fragmentaria, podría corresponderse con un área antroponímica bastante delimitada (Vallejo Ruiz 2005, p. 734) muy rica en testimonios onomásticos, transmitidos sobre todo en epígrafes latinos. A la luz de los datos, no habría inconveniente en considerar que ambos dominios (epigráfico y onomástico) se corresponden con una única realidad lingüística: el lusitano ${ }^{26}$. La coherencia antroponímica de la región está fuera de toda duda por las abundantes atestiguaciones de nombres exclusivos (Anderenus, Aranta, Arbura, Camira, Duatius, Leurius, Malgeinus, Pagusicus, Peidurtia, Sunua, Tanginus...), las características fonéticas propias (tendencia al betacismo, $u g>u, e>e i$ en ciertos contextos) o las peculiaridades derivacionales (abundancia de los sufijos en -e-to- u -o-ro-).

Esta coherencia se manifiesta incluso frente a otras lenguas del mismo lado de la frontera indoeuropea, como el celtibérico, con el cual existen pocas similitudes onomásticas entre los nombres mejor atestiguados, lo que se compadece bien con la idea de que nos encontramos ante áreas antroponímicas diferentes y, por tanto, ante lenguas diferentes. Un problema distinto (aunque no menor) es el de establecer la filiación de este lusitano: si bien una gran mayoría de los autores se inclinan a pensar en una rama independiente del celta, Untermann encabeza la lista de aquellos a quienes les persuade la idea de poder alinearla con las lenguas celtas, a pesar de no compartir todas las características canónicas del celta común (entre otras, la pérdida de * $p$ - inicial ${ }^{27}$.

Prácticamente el resto de los autores que se han dedicado de un modo más intensivo al estudio de los testimonios lingüísticos antiguos aceptan (yo mismo en Vallejo Ruiz 2005) una filiación no céltica de la lengua tradicionalmente llamada lusitano y de su antroponimia. Así también, De Bernardo 2002 acepta la existencia de una lengua lusitana no celta (expressis uerbis en pp. 91-92, n. 12), para lo que recurre al estudio de algunos antropónimos: el nombre Celtius (p. 92, n. 13), de origen étnico y supuestamente utilizado por

\footnotetext{
${ }^{26} \mathrm{La}$ abundancia de formas antroponímicas es una ayuda a la hora de afrontar un análisis fonético de conjunto; sin embargo, algunos términos clave del léxico se documentan sólo una vez, lo que no favorece ni su interpretación ni su análisis; sinceramente, creo que formas como ifadem u oilam deberían reinterpretarse a la luz de lo que conocemos ya de la fonética de los antropónimos lusitanos.

${ }^{27}$ En el apelativo porcom o en antropónimos como Peidurtia o Pagusicus. Véanse obras relativamente recientes como Untermann 1995, donde, en continuidad con su línea de pensamiento, defiende la celtidad de la onomástica hispana indoeuropea no celtibérica.
} 
gentes de origen celta en una región que no lo era, le sirve de elemento discriminador del área de habla no céltica, dado que este antropónimo circunscribe su distribución a la región lusitana, precisamente al área que ocupan los nombres citados algo más arriba. Si tenemos en cuenta las implicaciones de la aceptación de las áreas onomásticas (como hemos hecho hasta ahora), sorprende en cierto grado que P. de Bernardo utilice otros nombres con la misma distribución geográfica que Celtius o Sunua y los denomine «formas hispano-célticas» (pp. 105 y 106): sirvan como ejemplo del análisis de esta autora las formas Abrunus, Admata, Andamius (también en p. 112), Boutius (121), Cadarus (112), Catuenus (113 y 121), Caturo (114), Celtienus, Coria (116), Elandus, Equaesus, Mantua (91, n. 11), Matuenus (113), Pintamo-, Pissirus (105), Pistirus, Sailciecon (114), Tanginus (120, n. 147) Teuto o Toncius (119-120, n. 147). Además, incluye entre las formas hispano-célticas nombres como Ambatus $(102,117)$ o Cloutius (115) que, si bien no se limitan al área antroponímica lusitana, son difícilmente relacionables con la Celtiberia por las poquísimas atestiguaciones en esta región ${ }^{28}$. Si seguimos su argumentación hasta el final, el lusitano no contaría con un sistema antroponímico propio, o se habría visto absolutamente ocultado por la presencia de estos nombres «hispano-celtas».

En realidad, hay pocos indicios claros que nos permitan suponer origen celta para los nombres hispanos no celtibéricos: no hay criterios fonéticos que aseguren su pertenencia al grupo celta y, por otro lado, no hay ninguna coincidencia relevante con los antropónimos de Celtiberia (v. supra), única región epigráficamente celta de la que tengamos constancia en la Península Ibérica.

10. Creo, a pesar de algunas opiniones que no consideran de forma global todos los testimonios antroponímicos de una región, que la validez en la equiparación de área antroponímica y sistema lingüístico es innegable; por poner otro ejemplo de los disponibles en la Península Ibérica, citaré el «área vascona», que, aunque no cuente con una epigrafía propia en época antigua, sí dispone de un testigo moderno, la propia lengua vasca. El área antroponímica (revelada sólo a raíz de la interpretación por L. Michelena de los nombres de la estela de Lerga en 1961) presenta unas características fonéticas propias, como son, por citar sólo los datos más llamativos: caren-

\footnotetext{
${ }^{28}$ Para el análisis detallado de algunos nombres (de cuya interpretación discrepo en ocasiones), puede verse Vallejo Ruiz 2005, ss. uu.
} 
cia de fricativa labial $f$ y de semivocal $w$; estatus no fonológico de $p$ y de $m$; falta de $r$ - a comienzo de palabra; existencia de aspiración; presencia de silbantes que parecen indicar palatales y/o africadas, y un elenco propio aunque escaso: Nar- en Narhunges o Naru[---]eni, Abisun- en Abisunhari o Abisunsonis, Agir- en Agirnes, Agirsaris o Agirsenius, o el segundo elemento -hari(s) en Abisunhari o Dusanharis. Además, existen otros nombres determinantes como Sesenco, comparable a vasco actual zezen 'toro' con un sufijo - $k$ o diminutivo ${ }^{29}$.

11. Desgraciadamente, no quedan ya más territorios en los que comprobar la bondad de la ecuación de área antroponímica y sistema lingüístico, porque este último falta en el resto de las regiones y carecemos de otras lenguas modernas con las que comparar. La abundancia de nombres atestiguados en el marco de la epigrafía latina no encuentra comprobación en características lingüísticas transmitidas directamente en la Antigüedad (al contrario del celtibérico, el ibérico, el lusitano o la lengua del sudoeste) o de las mantenidas hasta hoy (como el vasco). Un caso claro lo constituye el «área astur» (quizá «cántabro-astur»), en la que se acumulan ciertas peculiaridades fonéticas (esbozadas en Vallejo Ruiz 2005, a falta de un análisis en profundidad): abundancia de sonorizaciones, eliminación de $-w$-intervocálica, paso de -ou$>-o-\ldots$ Un futuro estudio proporcionará el elenco de nombres que se atestiguan preferentemente en Asturias (entre los que parecen destacar Balaesus o Arocius $^{30}$ ) o los sufijos que usaron con más frecuencia.

En el estado actual de nuestros conocimientos (al menos de los míos) hay aún más dificultades a la hora de analizar la «región galaica», puesto que casi sólo podemos mencionar la abundante concentración de teónimos (y la inclusión de los castella en la fórmula onomástica), algo no exclusivamente lingüístico; sí puede mencionarse un listado de nombres exclusivos con más de una atestiguación: Adronus, Arus, Clutamus, Coralus, Corunis, Melgaecus, Nantius o Vecius. No me atrevo a asegurar que el galaico (al menos el del sur) fuera diferente del lusitano; al menos no lo haré hasta contar con un estudio exhaustivo de la región que supla las dificultades formales que presenta el

\footnotetext{
${ }^{29}$ Cf., por ejemplo, Gorrochategui 1995, 2002 ó 2006.

${ }^{30}$ Propios y casi exclusivos de Cantabria serían Acida, Boddus, Bouecius, Caelion- o Talanius. Nombres que comparten dispersión por territorios cántabros y astures serían Amparamus, Andotus, Caesaronus, Munigalicus u Origenus.
} 
material: mala calidad de la piedra (lo que dificulta las lecturas) y relativa escasez de epígrafes.

12. Otro conjunto onomástico sobre el que habría que fijar la atención en el futuro es el que J. Untermann ha venido considerando independiente al menos desde 1969. Se trata de una serie de nombres documentados tanto al norte como al sur de los Pirineos en la zona mediterránea; más concretamente, formas que no parecen corresponder a elementos y características apreciadas en las lenguas ibera o gala (atestiguaciones repetidas como Blaesius, luRtia, Pedanius, Velianius o radicales como bait-, baRt-, bobo-, bok-, Bot-, osat- o tika-, y los sufijos -elius o-anius); de acuerdo con las implicaciones del estudio de las áreas antroponímicas, deberían revelar la presencia de una lengua diferente en esos territorios. El mismo Untermann ha propuesto la denominación de «ligur» para este conjunto lingüístico, dotando al término de una acepción eminentemente geográfica, diferente de la que ha recibido tradicionalmente en los estudios de la Península Ibérica ${ }^{31}$. No obstante, serán los futuros estudios sobre estos elementos los que nos proporcionarán mayores certezas.

13. Por último, y siendo consciente de algunas limitaciones en la aplicación del método, puede decirse que el gran problema en los estudios de áreas antroponímicas antiguas, en especial el de aquellas que no cuentan con una epigrafía paralela, es el de la presencia de algunos antropónimos inespecíficos (Reburrus, Acca), documentados abundantemente en más de una región. Estudiando los nombres de lugar, un campo paralelo en el que la aplicación de este tipo de análisis podría resultar complementaria, J. Untermann publicó

\footnotetext{
${ }^{31}$ Este grupo de nombres y de sufijos al sur y norte de los Pirineos, sin ningún otro tipo de atestiguación, correspondería, en opinión de J. Untermann a un sistema lingüístico que propone denominar «ligur» $(1969,1973,1992,1995,2003)$. Correa 1993 estudió un conjunto de nombres que no hallaban paralelos en el repertorio estrictamente ibérico, pero que al parecer correspondía a dos lenguas, una de las cuales sería el galo y la otra la denominada ligur. De Hoz 1993 veía las inscripciones iberas del sur de los Pirineos (Castellón y Cataluña) y del norte (Languedoc) como secundarias, es decir, fruto de un uso como lengua vehicular relacionada con hábitos comerciales, puesto que su foco originario sería la zona de Alicante. Dado que la presencia de la lengua gala es tardía en la región narbonense, también parece ver con buenos ojos la presencia allí de una lengua liguroide (2005, p. 80). De Hoz quizá no hable en el mismo sentido que Untermann 2003, quien ponía objeciones a la falta de antigüedad del ibero en Cataluña, precisamente por la abundancia de antropónimos; De Hoz 2005 entiende éstos como préstamos.
} 
un estudio (2001) al hilo de la validez de la toponimia como fuente de las lenguas antiguas, en concreto de las hispano-celtas; en su reflexión mencionaba también una serie de elementos «inespecíficos» a la hora de definir una región desde el punto de vista onomástico. En el caso de la toponimia mencionaba -briga (utilizado incluso en híbridos latinos como Augustobriga) como elemento no caracterizador de un área, al igual que, para los hidrónimos, el formante -antia (presente prácticamente por toda la Península y en casi toda Europa $)^{32}$. No obstante, Untermann reconocía también que algunos topónimos podían ser claramente definitorios de una región, como los formados con Seg-, restringidos básicamente a la Celtiberia (2001, pp. 201-204).

Esto no choca necesariamente con la definición de área onomástica; estos nombres inespecíficos, considerados en conjunto con el resto de la lista onomástica de una región, no son obstáculos insalvables; a pesar de que variantes como Ambatus y Ambadus, Reburrus y Reburus, Dobiterus, Douiterus y Doiderus correspondan al mismo nombre en origen, la especial adaptación de las diferentes variantes guarda gran relación con la lengua hablada en cada región: no hallo Ambadus o Doiderus fuera de la región astur, lo mismo que no encuentro Dobiterus fuera de Lusitania. Está, sin embargo, fuera de toda duda que, frente a ellos, los circunscritos claramente a una región geográfica (Tancinus en Lusitania, Letondo en Celtiberia u Ordumeles en territorio ibérico, al igual que los topónimos con Seg- en Celtiberia) y, sobre todo, su abundancia ayudan en mayor medida al acotamiento del área.

Quisiera resumir, a modo de cierre, algunas de las ideas que vertebran este ensayo, y que no son sino la extensión lógica de la aceptación del concepto de área antroponímica: la primera es la de que un nombre aislado no sirve para un estudio etimológico, precisamente por la ausencia de semántica que he mencionado unas páginas atrás ${ }^{33}$. La segunda es que un nombre no puede

\footnotetext{
${ }^{32}$ También recordaba que entre los antropónimos hallamos algunos casos como Tritius, Calaetus, Boutius, Arquius, Arco o Louc-, que no sirven para definir, por sí solos, un área onomástica.

${ }^{33}$ Aunque analizáramos un único nombre en términos de pertenencia a un área antroponímica y no con un prisma etimológico, las conclusiones que de ello sacaríamos serían débiles. Voy a permitirme traer un ejemplo que sirvió de estudio a Villar 1994, como es el de los nombres con la raíz Pent-: las variantes con -e- (Pentius y Pentouius, nombres cántabro-astures) y las que tienen - $i$ - (como Pintamus, lusitano-galaico) supondrían la existencia de dos dominios lingüísticos, uno lusitano y otro relacionado con otra lengua indoeuropea no celta. Las razones que llevan a Villar a rechazar las lenguas celtas son etimológicas (probablemente el nombre
} 
desgajarse de su área antroponímica (a través de la cual se encuentra unido al grupo) y que, por consiguiente, no se pueden mezclar en el análisis nombres de distintas áreas. Estas ideas me conducen a reiterar mi más sincera convicción sobre la validez de la antroponimia como fuente de estudio de las lenguas antiguas, y a expresar mi deseo de que los futuros estudios globales y pormenorizados de las áreas onomásticas contribuyan (aunque sólo sea limitadamente) al estudio de las lenguas de la Antigüedad.

\section{BiBLIOGRAFÍA}

$A c S=$ Holder, A. 1896, 1904, 1907: Alt-celtischer Sprachschatz, 3 vols., Graz (reimp. 1961-1962).

Albertos Firmat, M. ${ }^{a}$ L. 1965: «Nuevos antropónimos hispánicos», Emerita 33, pp. 109-143.

- 1966: La onomástica personal primitiva de Hispania: Tarraconense y Bética, Salamanca.

- 1976: «La antroponimia prerromana en la Península Ibérica», en Jordá, F., Hoz, J. de y Michelena, L. (eds.), Actas del I Coloquio sobre lenguas y culturas prerromanas de la Península Ibérica (Salamanca, 27-31 de mayo de 1974), Salamanca, pp. 57-86.

Alföldy, G. 1964: «Die Namengebung in der römischen Provinz Dalmatia», Beiträge zur Namenforschung 15, pp. 55-104.

Bernardo Stempel, P. de 2002: «Centro y áreas laterales: la formación del celtibérico sobre el fondo del celta peninsular hispano», Palaeohispanica 2, pp. 89-132.

CIL VIII = Corpus inscriptionum Latinarum, vol. VIII, Inscriptiones Africae Latinae.

Correa, J. A. 1993: «Antropónimos galos y ligures en inscripciones ibéricas», en Adiego, I.-J., Siles, J. y Velaza, J. (eds.), Studia Palaeohispanica et Indogermanica J. Untermann ab amicis oblata, Barcelona, pp. 101-116.

Dondin-Payre, M. y Raepsaet-Charlier, M.-Th. (eds.) 2001: Noms, identités culturelles et romanisation sous le Haut-Empire, Bruselas.

Evans, D. E. 1964: «Some Celtic Personal Names in the Commentaries on the Gallic War», BBCS 21, 1, pp. 1-17.

tiene relación con el ordinal *penkwtó- 'quinto', no reducible a las lenguas celtas); las razones que lo llevan a separar dos dominios lingüísticos están basadas en la diferente dispersión de dos variantes de una sola raíz. Aunque las apreciaciones de Villar son seguramente correctas, es el análisis de conjunto de toda la onomástica el que debe llevarnos a más seguras conclusiones. 
Gómez Moreno, M. 1949: Misceláneas. Historia, Arte, Arqueología. Primera serie: la antigüedad, Madrid.

Gorrochategui, J. 1995: «Los Pirineos entre Galia e Hispania: las lenguas», Veleia 12, pp. 181-234.

- 2002: «Las lenguas de los Pirineos en la Antigüedad», en Els substrats de la llengua catalana: una visió actual. Treballs de la Societat Catalana de Llengua y Literatura, 1, Barcelona, pp. 75-101.

- 2006, «Onomástica vascónica y aquitana: elementos para el conocimiento de la Historia Antigua de Navarra», en Andreu Pintado, J. (ed.), Navarra en la Antigüedad. Propuesta de actualización, Pamplona, pp. 111-134.

Hoz, J. de, 1989: «El desarrollo de la escritura y las lenguas de la zona meridional», en Aubet, M. E. (coord.), Tartessos. Arqueología protohistórica del Bajo Guadalquivir, Sabadell, pp. 523-587.

- 1993: «La lengua y la escritura ibéricas, y la lengua de los íberos», en Untermann, J. y Villar, F. (eds.), Lengua y cultura en la Hispania prerromana. Actas del V Coloquio sobre lenguas y culturas prerromanas de la Península Ibérica (Colonia, 25-28 de noviembre de 1989), Salamanca, pp. 635-666.

- 2005: «Epigrafías y lenguas en contacto en la Hispania antigua», en Velaza, J., Beltrán, F. y Jordán, C. (eds.), Acta Palaeohispanica IX. Actas del IX Coloquio sobre lenguas y culturas paleohispánicas (Barcelona, 20-24 de octubre de 2004), Palaeohispanica 5, Zaragoza, pp. 57-98.

Humboldt, W. von 1821: Prüfung der Untersuchungen über die Urbewohner Hispaniens vermittelst der baskischen Sprache, Berlín (trad. española de F. Echebarría, Primitivos pobladores de España y lengua vasca, Madrid, 1959).

IEW = Pokorny, J. 1959: Indogermanisches etymologisches Wörterbuch, Berna-Múnich.

Kajanto, I. 1965: The Latin Cognomina, Helsinki (Roma, 1982).

— 1967: «A note on the problem of sustratum», Beiträge zur Namenforschung. Neue Folge 2, pp. 3-12.

Katičić, R. 1963: «Das mitteldalmatische Namengebiet», Živa Antika 12, pp. 255 292.

- 1965: «Zur frage des keltischen und pannonischen Namengebiete im römischen Dalmatien», Centar za Balkanoloska Ispitivanja, pp. 53-76.

Lefebvre, S. 2001 : «Á propos de la répartition du nom Verecundus en Gaule et en Germanie», en Dondin-Payre, M. y Raepsaet-Charlier, M.-Th. (eds.), Noms, identités culturelles et romanisation sous le Haut-Empire, Bruselas, pp. 597-647.

Michelena, L. 1961: «Los nombres indígenas de la inscripción hispanorromana de Lerga», Príncipe de Viana 22, pp. 65-74.

MLH = Untermann, J. 1975-2000: Monumenta Linguarum Hispanicarum. I: Die Münzlegenden (1975), II: Die Inschriften in iberischer Schrift in Südfrankreich 
(1980), III: Die iberischen Inschriften aus Spanien (1990), IV: Die tartessischen, keltiberischen und lusitanischen Inschriften (1997), V. 1 (Wodtko, D.): Wörterbuch der keltiberischen Inschriften (2000), Wiesbaden.

Navarro, M., Oria, M. y Ramírez, J. L. 2003: «Eje 3. La onomástica greco-latina», en Grupo Mérida, Atlas antroponímico de la Lusitania romana, Mérida-Burdeos, pp. 407-412.

OPEL I = Lörincz, B. y Redö, F. 1994: Onomasticon prouinciarum Europae Latinarum. I: Aba-Bysanus, Budapest.

OPEL II = Lörincz, B. 1999: Onomasticon prouinciarum Europae Latinarum. II: Cabalicius-Ixus, Viena.

OPEL III = Lörincz, B. 2000: Onomasticon prouinciarum Europae Latinarum. III: Labareus-Pythea, Viena.

OPEL IV = Lörincz, B., 2002: Onomasticon prouinciarum Europae Latinarum, IV: Quadratia-Zures, Viena.

Pulgram, E. 1954: «Theory of names», Beiträge zur Namenforschung 5, pp. 149-196.

Raepsaet-Charlier, M.-T. 1995: «Aspects de l'onomastique en Gaule Belgique», Cahiers Glotz 6, pp. 207-226.

Rubio Alija, J. 1959: «Españoles por los caminos del imperio romano. Estudios epigráfico-onomásticos en torno a Reburrus y Reburrinus», Cuadernos de Historia de España 29-30, pp. 5-124.

Untermann, J. 1961a: Sprachräume und Sprachbewegungen im vorrömischen Hispanien, Wiesbaden.

- 1961b: Die venetischen Personennamen, Wiesbaden.

- 1962: «Personennamen als Sprachquelle im vorrömischen Hispanien», en II. Fachtagung für indogermanische und allgemeine Sprachwissenschaft (Innsbruck, 10.-15. Oktober 1961), Innsbrucker Beiträge zur Kulturwissenschaft, Sonderheft 15, pp. 63-93.

- 1963: «Estudio sobre las áreas lingüísticas pre-romanas de la Península Ibérica», Archivo de Prehistoria Levantina 10, pp. 165-192.

- 1965: Elementos de un atlas antroponímico de la Hispania antigua, Madrid.

— 1969: «Lengua gala y lengua ibérica en la Galia Narbonensis», Archivo de Prehistoria Levantina 12, pp. 99-161.

- 1973: «Le nom de Narbonne et la langue de ses habitants», Narbonne. Archéologie et histoire. Fédération historique du Languedoc méditerraneèn et du Rousillon, Montpellier, pp. 163-167.

- 1987: «Repertorio antroponímico ibérico», Archivo de Prehistoria Levantina 17, pp. 289-318.

- 1992: «Quelle langue parlait-on dans l'Hérault pendant l'Antiquité?», Revue Archéologique de Narbonnaise 25, pp. 19-27. 
Untermann, J. 1995: «Lengua y poblamiento prerromano en el territorio celtibérico», en Burillo, F. (coord.), Poblamiento celtibérico. III Simposio sobre los celtíberos, Zaragoza.

- 1998: «La onomástica ibérica», Iberia 1, pp. 73-85.

- 2001: «La toponimia como fuente de las lenguas hispano-celtas», Palaeohispanica 1 , pp. 187-218.

- 2003: «Los vecinos de la lengua ibérica: galos, ligures, tartesios, vascones», en Torallas, S. (ed.), Memoria. Seminarios de Filología e Historia, Madrid.

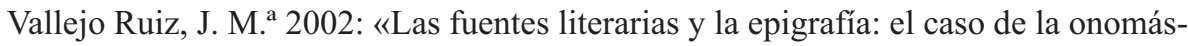
tica personal», en Hernández Guerra, L., Sagredo, L. y Solana, J. M. a (eds.), Actas del I Congreso Internacional de Historia Antigua: La Península Ibérica hace 2000 años (Valladolid, 23-25 de noviembre de 2000), Valladolid, pp. 401-407.

- 2005: Antroponimia indígena de la Lusitania romana, Vitoria-Gasteiz.

Velaza Frías, J. 1996: Epigrafía y lengua ibéricas, Madrid.

Villar, F. 1994: «Los antropónimos en Pent-, Pint- y las lenguas indoeuropeas prerromanas de la Península Ibérica», en Bielmeier, R. y Stempel, R., Indogermanica et Caucasica, Festschrift für Karl Horst Schmidt zum 65. Geburtstag, Berlín-Nueva York, pp. 234-264.

Weisgerber, J. L. 1969: Rhenania Germano-Celtica, Bonn.

Fecha de recepción de la primera versión del artículo: 14/02/2008

Fecha de aceptación del artículo: 14/07/2008

Fecha de recepción de la versión definitiva del artículo: 22/01/2009 